\title{
PD14 - Non-interventional 2-year study of sublingual immunotherapy in children and adolescents with allergic rhinoconjunctivitis caused by grass pollen
}

\author{
Efstrathios Karagiannis ${ }^{1 *}$, Kija Shah-Hosseini ${ }^{2}$, Meike Hadler ${ }^{1}$, Ralph Mösges ${ }^{2}$ \\ From 3rd Pediatric Allergy and Asthma Meeting (PAAM) \\ Athens, Greece. 17-19 October 2013
}

\section{Background}

The aim of this non-interventional study was to document the impact of a sublingual allergen immunotherapy (AIT) with Oralair 5-grass pollen tablets (Stallergenes, France) on symptom severity, use of symptomatic medication and tolerability in patients with grass pollen-induced allergic rhinoconjunctivitis (RC) over 2 years of routine medical practice treatment. This poster focuses on the subgroups of children (4-11 yrs) and adolescents (12-17 yrs).

\section{Methods}

This prospective, open, non-controlled, non-interventional, multicenter study was conducted from September 2010 to October 2012 in Germany. Overall 1.482 patients (248 children (16.9\%), 201 adolescents (13.7\%)) participated in the study.

The patients rated their symptoms as a combined score of severity (scale: 0 [none] -3 [severe]) and frequency (scale: 0 [none] -4 [very often]). In the combined RC score, the severity of rhinitis and conjunctivitis were pooled (scale: 0 [none] - 6 [severe]).

\section{Results}

During the season preceding AIT treatment $88 / 85 \%$ of children/ adolescents had used symptomatic medication. This rate dropped to $57 / 56 \%\left(1^{\text {st }}\right.$ season) and to $48 / 40 \%$ $\left(2^{\text {nd }}\right.$ season). Likewise the RC score decreased from 4.10/ 4.05 to $1.93 / 1.97$ ( $1^{\text {st }}$ year) and to $1.39 / 1.39$ ( $2^{\text {nd }}$ year).

An improvement in health status after two years of treatment was documented by $96 / 97 \%$.

${ }^{1}$ Stallergenes GmbH, Kamp-Lintfort, Germany

Full list of author information is available at the end of the article
Adverse events occurred in $17.7 / 20.2 \%$ over two years of treatment. The incidence of non-fatal serious adverse events was $1.2 / 0.0 \%$.

At the end of the $2^{\text {nd }}$ season, $96 / 97 \%$ evaluated the tolerability of the 5-grass pollen tablets as very good or good.

For the group of monoallergic children/ adolescents, the RC score was reduced from 4.05/ 3.63 to $1.95 / 1.85$ $\left(1^{\text {st }}\right.$ year $)$ to $1.29 / 1.10$ ( $2^{\text {nd }}$ year $)$. The RC score in polyallergic children/ adolescents decreased from 4.09/ 4.17 to $1.94 / 2.03\left(1^{\text {st }}\right.$ year $)$ to $1.46 / 1.50$ ( $2^{\text {nd }}$ year $)$.

\section{Conclusion}

Based on the study results, AIT with Oralair 5-grass pollen tablets was well tolerated by children and adolescents in routine medical practice. All symptom scores and the symptomatic medication use were reduced significantly after one and two years under treatment with Oralair 5-grass pollen tablets compared to the season preceding AIT. Polyallergic children and adolescents benefited as much from AIT as the monoallergic ones.

\section{Authors' details \\ 'Stallergenes GmbH, Kamp-Lintfort, Germany. ${ }^{2}$ Institute of Medical Statistics, Informatics and Epidemiology (IMSIE), University Hospital Cologne, Cologne,} Germany.

Published: 28 February 2014

doi:10.1186/2045-7022-4-S1-P14

Cite this article as: Karagiannis et al:: PD14 - Non-interventional 2-year study of sublingual immunotherapy in children and adolescents with allergic rhinoconjunctivitis caused by grass pollen. Clinical and Translational Allergy 2014 4(Suppl 1):P14. 